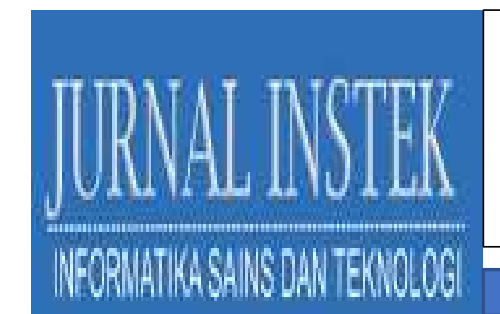

Volume 6 Nomor. 1, April 2021

P-ISSN : 2541-1179, E-ISSN : 2581-1711

Ojs :http://journal.uin-alauddin.ac.id/index.php/instek/index

Email : instek@uin-alauddin.ac.id

\title{
TEKNIK WATERMARKING MENGGUNAKAN METODE LEAST SIGNIFICANT BIT PADA CITRA UNTUK PERLINDUNGAN HAK CIPTA MOTIF BATIK
}

\section{WIDIYONO ${ }^{1}$, ARI PUTRA WIBOWO ${ }^{2}$, ARIEF SOMA DARMAWAN ${ }^{3}$}

\author{
Teknik Informatika, ${ }^{1,2,3}$ \\ STMIK Widya Pratama \\ Jl. Patriot No 25 Pekalongan \\ email: widdyono@gmail.com ${ }^{1}$, ariputra.stmikwp@gmail.com² ${ }^{2}$, \\ soma98980@yahoo.com ${ }^{3}$
}

\begin{abstract}
ABSTRAK
Batik merupakan karya seni yang dijadikan kultur budaya asli Indonesia. Sehingga batik dikenal dunia sebagai ciri khas Indonesai, dengan banyak sekali motif yang beranekaragam. Keanekargaman motif batik merupakan khas dari masing-masing daerah se-Indonesia. Motif Batik Pekalongan memiliki khas keanekaragman warna, perpaduan motif alam, dan motif moderen. Pada era digital pemasaran batik melalui marketplace yang telah menjangkau dunia dengan tidak terbatas. Tetapi motif batik digital rawan untuk dimanipulasi sehingga diperlukan perlindungan hak cipta motif batik secara digital. Untuk itu pada penelitian ini dilakukan perancangan dan pengembangan aplikasi watermarking dengan menggunakan metode Least Signnificant Bit (LSB). Pembuatan aplikasi watermarking pada penelitian ini menggunakan bahasa pemrograman java dengan netbeans versi 7.4. Dari sistem aplikasi watermarking yang dirancang dilakukan pengujian, bahwa aplikasi ini dapat berfungsi dengan baik sebagai solusi untuk perlidungan hak cipta motif batik.
\end{abstract}

Kata Kunci: Least Significant Bit, Motif Batik, Watermaking,

\section{PENDAHULUAN}

Batik merupakan karya seni yang dijadikan kultur budaya asli Indonesia. Sehingga batik dikenal dunia sebagai ciri khas Indonesia yang memiliki motif beranekaragam. Keanekargaman motif batik merupakan ciri khas dari masingmasing daerah se-Indonesia. Motif Batik Pekalongan memiliki khas keanekaragaman warna, perpaduan motif alam, dan motif modern. Beberapa motif batik yang terkenal dari Pekalongan antara lain motif jelamprang, motif liong dan motif semen. Keistimewaan lain dari batik Pekalongan adalah para pengrajin batik selalu mengikuti perkembangan jaman dalam membuat kreasi karya motif batik. Pada era digital seperti sekarang ini pemasaran produksi batik banyak dilakukan lewat marketplace yang telah menjangkau dunia dengan tidak terbatas. Namun hal 


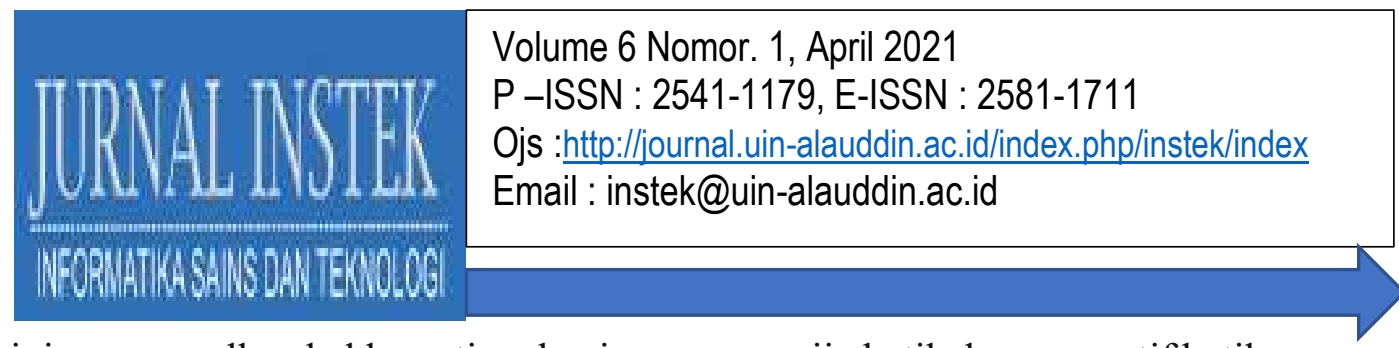

ini memunculkan kekhawatiran bagi para pengrajin batik, karena motif batik rawan ditiru atau dimanipulasi. Untuk itu seharusnnya karya motif batik berupa citra digital bisa dipatenkan agar tidak ditiru pihak yang lain.

Karya motif batik merupakan suatu yang penting bagi para pengrajin batik, baik karya dari perorangan maupun perusahaan. Di era digital seperti saat ini, banyak karya motif batik yang dimanipulasi dan bahkan digunakan oleh pihak lain yang tidak bertanggung jawab demi memperoleh keuntungan. Hal ini tentunya sangat merugikan bagi pengrajin yang telah menciptakan motif batik. Keaslian gambar (motif batik) menjadi salah satu permasalahan yang cukup penting, sebagai dampak dari perkembangan teknologi informasi. Ketersediaan data yang sangat banyak dalam bentuk digital memudahkan data untuk dirubah atau bahkan dirusak dengan alat pengolah gambar sehingga gambar yang diperoleh dari internet belum tentu keasliannya. Perlindungan hak cipta atau paten dari suatu hasil karya menjadi hal yang penting untuk memastikan kepemilikan, copy right dan keaslian.

Salah satu solusi yang bisa digunakan untuk melindungi hak cipta pada citra adalah dengan menerapkan teknik watermarking. Watermarking merupakan teknik menyisipkan pesan (embed) pada citra sehingga keaslian dari citra tersebut masih bisa terdeteksi. Penyisipan tanda atau watermarking tidak akan merusak data digital yang dilindungi. Pesan yang sudah disisipkan pada data digital tidak dapat dihapus, sehingga jika ada data digital yang memiliki watermarking digandakan dan disebar, otomatis data digital tersebut masih bisa terdeteksi karena watermarking di dalam data digital tersebut ikut terbawa. Penyisipan pesan atau teknik watermarking ini dapat diterapkan pada teks, gambar citra, audio, video dan sebagainya.

Teknik watermaking yang paling sederhana dan mudah diimplementasikan adalah Least Significant Bit (LSB). Pada metode LSB dilakukan penyisipan pesan (embed) pada gambar citra yang akan dijaga keasliannya. LSB bekerja dengan cara menyisipkan pesan berupa bit pada bilangan bit yang paling kecil atau bit yang paling kanan pada data piksel yang menyusun dokumen citra asli. Sehingga proses ini tidak akan merubah citra secara kasat mata, namun masih bisa dikenali oleh 
komputer.

\section{METODE PENELITIAN}

Metodologi penelitian merupakan proses menganalisa masalah, mengumpulkan data baik itu studi lapangan ataupun literatur, melakukan identifikasi masalah dan identifikasi kebutuhan, mendesain dan mebangun aplikasi sampai melakukan penarikan kesimpulan dari permasalahan yang di teliti.

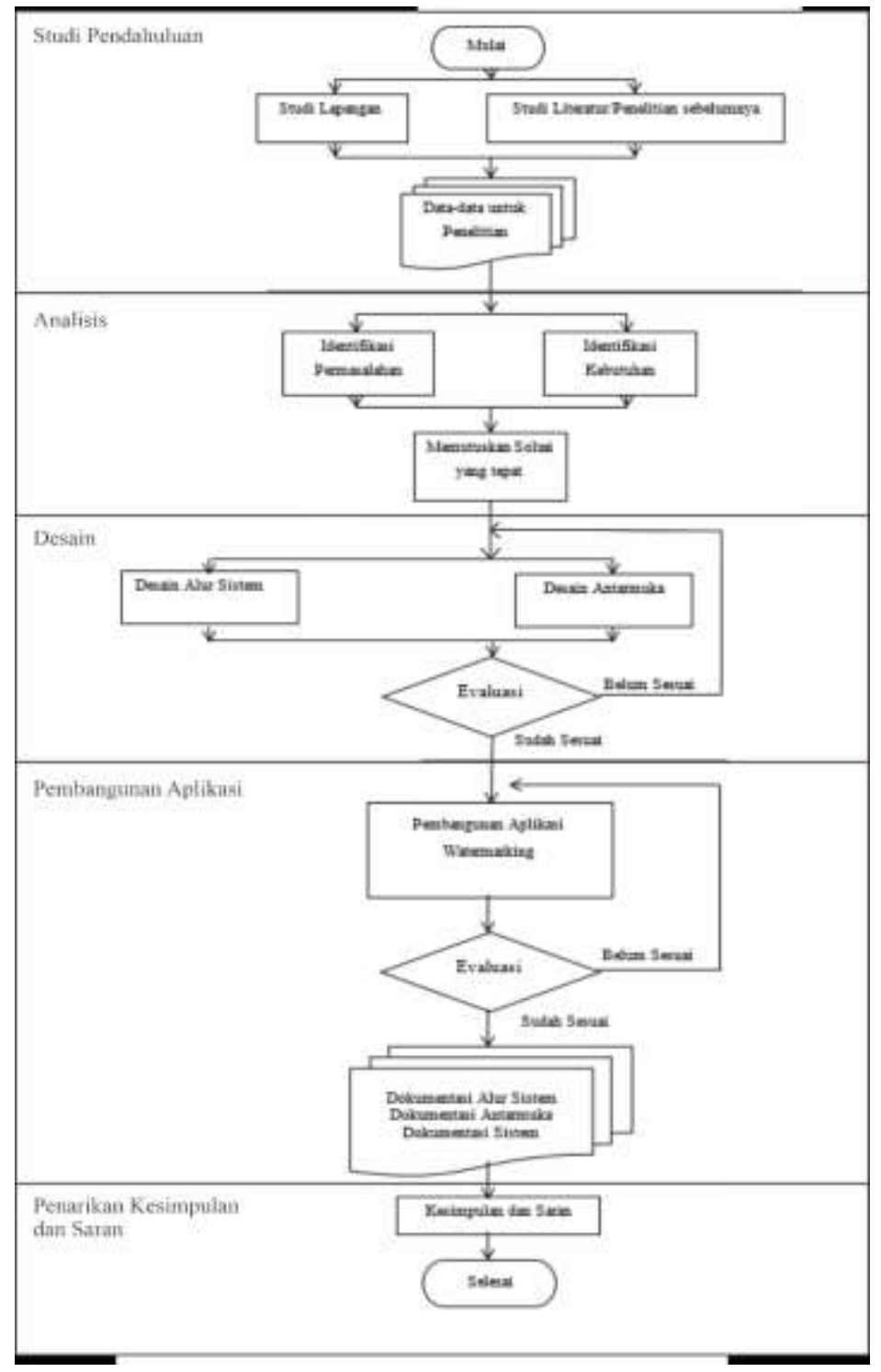

Gambar 1. Metode Penelitian 
Gambar 1 menunjukkan tahapan metode penelitian yang dilakukan, terdapat 5 (lima) tahap dalam melaksanakan penelitian ini.

1. Desain Alur Proses Sistem

a. Proses Penyisipan (Embed)

Proses penyisipan pesan pada citra digital terdapat 3 (tiga) inputan yaitu gambar citra asli, pesan dan kata kunci (password). Gambar 2 berikut ini merupakan alur embeding.

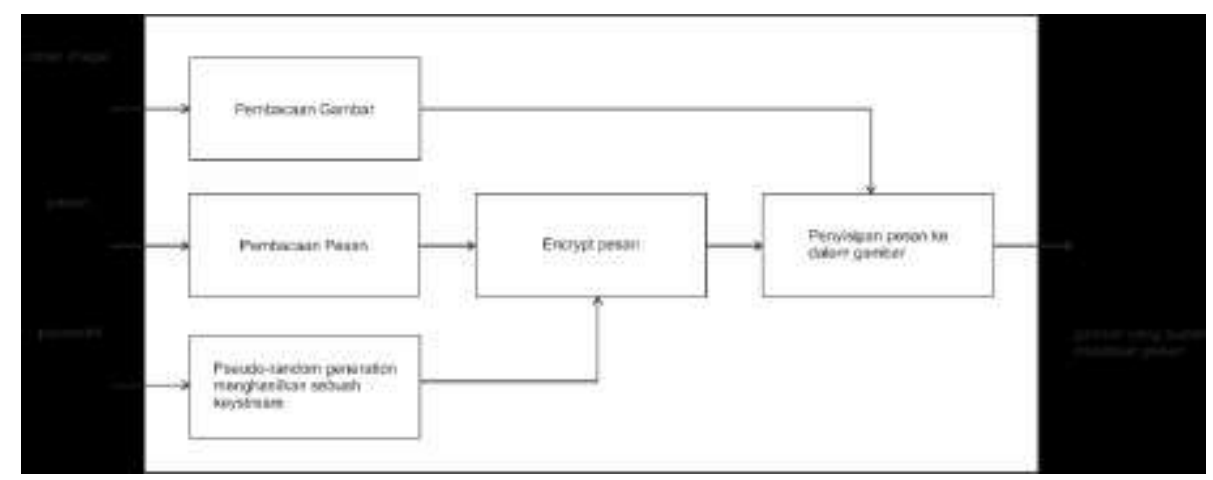

Gambar 2. Alur proses embed

Gambar 2 menunjukkan proses penyisipan pesan ke gambar citra :

1) Mengidentifikasi citra digital yang diinput dan merubah file citra digital menjadi byte

2) Mengidentifikasi pesan dan merubah menjadi byte

3) Mengidentifikasi kata kunci (password) dan melakukan pseudorandom generation untuk menghasilkan keystream

4) Melakukan enskripsi byte pesan dengan logika XOR pada byte pada keysteam

5) Menyisipkan byte pesan yang telah dienskripsi ke dalam citra digital

6) Menyusun ulang byte pada citra digital menjadi stego (watermark)

b. Proses Ekstraksi (Extract)

Proses ekstraksi pesan pada citra digital terdapat 2 (dua) inputan yaitu gambar stego dan kata kunci (password). Gambar 3 berikut ini 
merupakan proses exrtaksi.



Gambar 3. Alur proses extract

Gambar 3 menunjukkan proses ekstraksi dari gambar stego :

1) Mengidentifikasi gamabr stego dan mengubah menjadi byte

2) Memisahkan byte gambar dan byte pesan

3) Mengidentifikasi kata kunci (password) dan melakukan pseudorandom generation untuk menghasilkan keystream

4) Melakukan dekripsi byte pesan dengan logika XOR tiap byte pesan dengan byte keystream

5) Mengubah byte hasil deskripsii menjadi file.

\section{HASIL PENELITIAN}

Setelah dilakukan tahapan-tahapan sesuai metode penelitian, dihasilkan aplikasi watermarking untuk perlindungan citra batik yang dijalankan pada perangkat laptop ataupun pc. 
Volume 6 Nomor. 1, April 2021

P-ISSN : 2541-1179, E-ISSN : 2581-1711

Ojs :http://journal.uin-alauddin.ac.id/index.php/instek/index

Email : instek@uin-alauddin.ac.id

क. FORM SIFGANOGRAPH
Home EMbGd Entact

\section{Aplikasi WaterMaking}

Cra Mengounakan Apeicasi Watermavong

\section{A. MENU EMBED}

1. Menu Embed digunakas untuk melaintan enksipsi gambar, dan hasll dart enknosi

2. Pada menu embed terdapat beberapa lombol diantaranya

a. Tomool Add File Digunakan untuk memasuban flie yang akan dieniknpa ke gampar.

b. Tomool Cover image : Digunakan untuk memasublan gambar yang akan djadikan cover ankipipsi.

c. Tombel Set Pasaword: Digunakan untuk memasukkan pasaword dari hasi gambar stego.

d. Tombol Embed Digunakan untuk molaikikan proses embedding

3. Pada menvembed lerdacat dua paner yaitu.

a. Panel Cover Image : Menampikan gambar cover yang aran digutiakan

b. Panei Watormaing image - Monamplkan gambar hasl proses Empodang

4. Gambor Wotormaking akan tersimpan daiam sebuah folder Watertiakingimage yang otomatis akan membuat toider to

B. MENU EXTRACT

1. Menu Extract digunakan unhuk, meiakukan decoypt gambar Watermaing

2. Pada menu extract terdapat beberapa tombol diantaranya:

a. Tomacl Add Watermak image Digunakan urhuk memasukan file stego image yang akan a of

D. Tombol Extract Digunakan untuk melakukan decript

3. Pada menu extract terdapat beberapa fieldi diantaranya

a. Field Password Digunakan untuk memasukkan password stego image yano dombed. $+$

Gambar 4. Tampilan home aplikasi watermarking

Gambar 4 menunjukkan tampilan home pada aplikasi watermarking. Pada menu home ini berisi tentang penggunaan aplikasi watermarking.

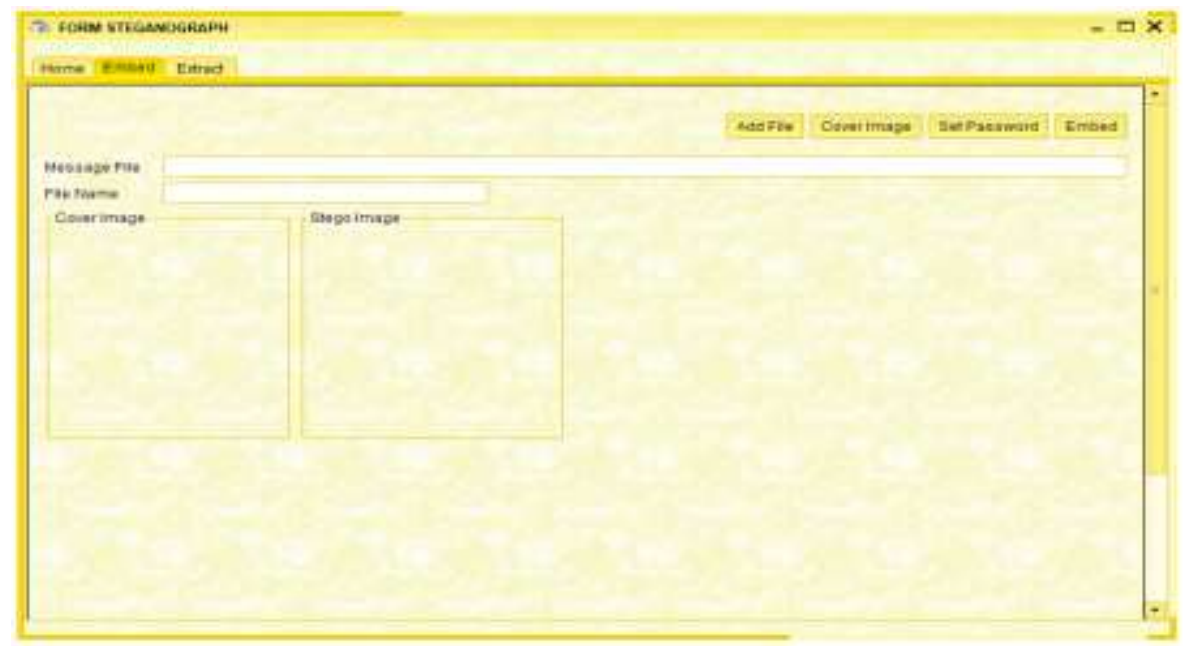

Gambar 5. Tampilan menu embed aplikasi watermarking 

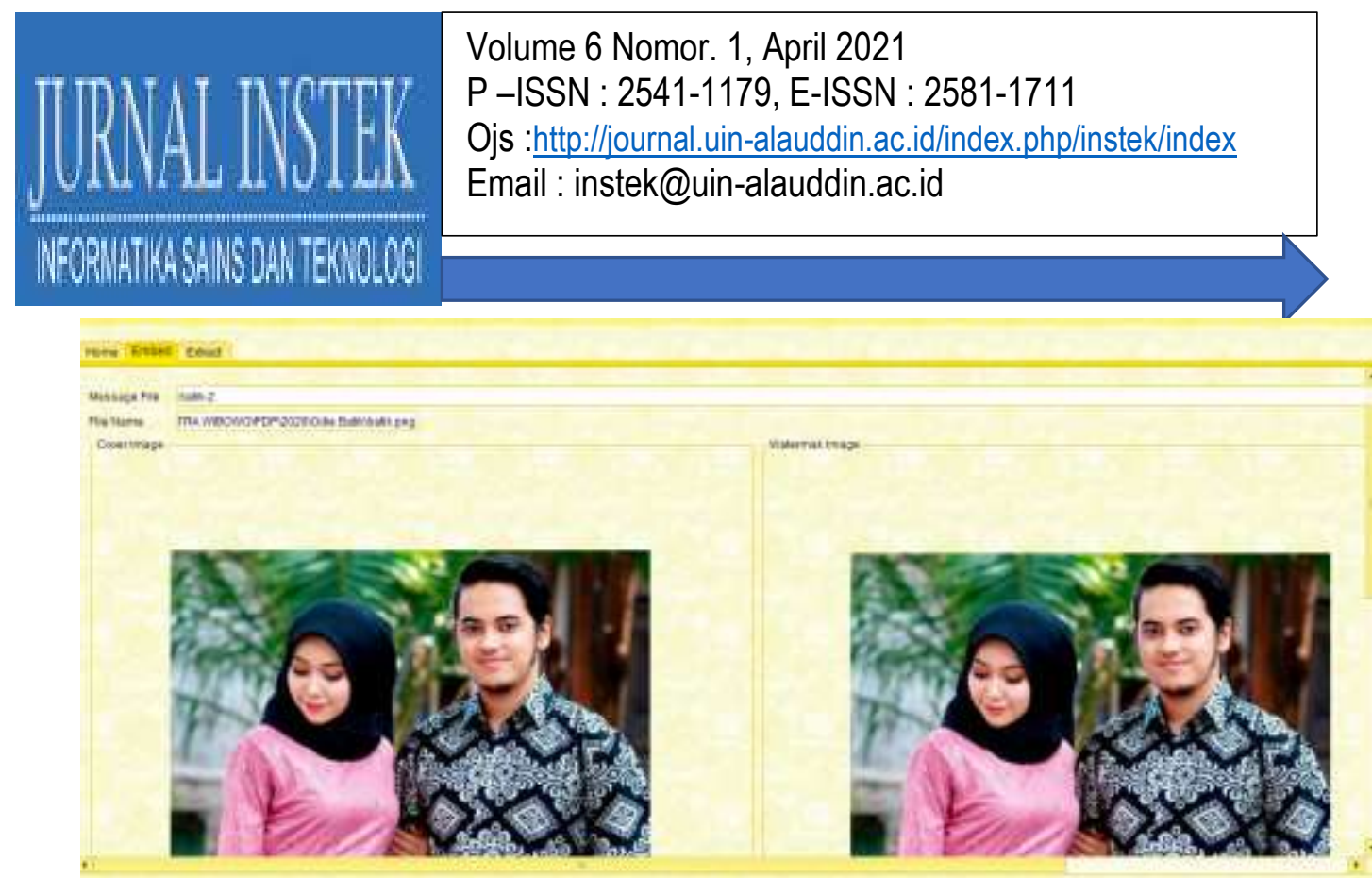

Gambar 6. Proses embed pesan ke image



Gambar 7. Tampillan menu extract aplikasi watermarking

\section{PEMBAHASAN}

Penelitian ini menghasilkan sebuah aplikasi watermarking yang dapat digunakan untuk melindungi hak cipta dari motif batik.

1. Dari tahap pengumpulan data dilakukan dengan observasi ke pengusaha batik (odie batik) pekalongan terkait dengan pengelolaan citra batik dalam menjalankan usaha toko online. Selain melakukan pengumpulan data secara langsung dalam mendukung penelitian ini juga dilakukan studi 
literatur atau pengumpulan artikel-artikel sebelumnya yang berkaitan dengan watermarking.

2. Pada tahap analisis dilakukan identifikasi masalah, permasalahan yang ada adalah belum adanya pengelolaan citra batik yang digunakan dalam toko online sehingga motif batik pada citra batik ditiru atau dimanipulasi pihak yang tidak bertanggung jawab.

3. Pada tahap desain melakukan rancangan alur sistem aplikasi menggunakan flowchart dan merancang tampilan aplikasi yang user friendly agar mudah digunakan.

4. Pembangunan aplikasi pada penelitian ini dibuat dengan menggunakan bahasa pemrograman java dengan aplikasi netbeans versi 7.4, pengujian dilakukan untuk mengetahu aplikasi ini berjalan dengan baik dan tidak terjadi error sebelum aplikasi watermarking ini didistribusikan ke pengguna.

\section{KESIMPULAN}

Dari hasil pengujian yang sudah dilakukan pada tahap pembangunan sistem aplikasi dapat disimpulkan bahwa aplikasi dapat dijalankan dengan baik sesuai dengan yang diharapkan. Namun, aplikasi watermarking ini masih perlu dilakukan pengembangan untuk meningkatkan keamanan pesan.

\section{DAFTAR PUSTAKA}

Ariyus, Keamanan Multimedia. Yogyakarta: Andi, 2009.

B. W. A. Putro and Febriani, "Aplikasi Watermarking Dengan Metode Least Significant Bit Menggunakan Matlab,” J. Ilm. Inform. Komput., vol. 21, no. 3, pp. 1-7, 2017.

F. Rakhmat, "Steganografi menggunakan metode least significant Bit dengann kombinasi algoritma kriptografi Vigenere dan RC4," Din. Inform., vol. 5, 2010 
Volume 6 Nomor. 1, April 2021

P-ISSN : 2541-1179, E-ISSN : 2581-1711

Ojs :http://journal.uin-alauddin.ac.id/index.php/instek/index

Email : instek@uin-alauddin.ac.id

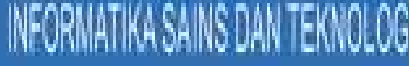

F. Masykur, "Implementasi Watermarking Metode LSB Pada Citra Guna Perlindungan Karya Cipta," vol. 5, no. 3, pp. 28-32, 2016.

N. Herawati, "Teknik Watermarking Menggunakan Metode Crt Pada Deteksi Tepi Canny Untuk Perlindungan Hak Cipta (DAGADU)," vol. 11, no. 2, pp. 167-172, 2019.

N. U. R. E. Trimargawati, "Penerapan hukum hak cipta seni batik pekalongan sebagai komoditas internasional," pp. 1-30, 2010.

R. E. Putri, “Bicara Pekalongan, Bicara Batik,” www.kompasiana.com, 2016. [Online]. Available:

https://www.kompasiana.com/ratuerdinaputri/575da9bb519773201797364 7/bicara-pekalongan-bicara-batik.

R. Munir, "Sekilas Image Watermarking untuk Memproteksi Citra Digital dan Aplikasinya pada Citra Medis,” 2012. 